\title{
Control of nucleolar stress and translational reprogramming by IncRNAs
}

\author{
Yvessa Verheyden ${ }^{1}$, Lucas Goedert ${ }^{1,2}$ and Eleonora Leucci ${ }^{1, *}$ \\ ${ }^{1}$ Laboratory of RNA Cancer Biology, Department of Oncology, LKI, KU Leuven, 3000 Leuven, Belgium. \\ ${ }^{2}$ Department of Cell and Molecular Biology, Faculty of Medicine of Ribeirão Preto, University of São Paulo, Ribeirão Preto, São Paulo, \\ Brazil. \\ * Corresponding Author: \\ Prof. Eleonora Leucci, Laboratory for RNA Cancer Biology, Department of Oncology, KU Leuven, Campus Gasthuisberg, Onderwijs \& \\ Navorsing I, Herestraat 49, bus 818, room 06.423, 3000 LEUVEN; Phone: +32 0163301 16; E-mail: eleonora.leucci@kuleuven.be
}

\begin{abstract}
Under adverse environmental conditions, cells activate stress responses that favour adaptation or, in case of irreversible damage, induce cell death. Multiple stress response pathways converge to downregulate ribosome biogenesis and translation since these are the most energy consuming processes in the cell. This adaptive response allows preserving genomic stability and saving energy for the recovery. It follows that the nucleolus is a major sensor and integrator of stress responses that are then transmitted to the translation machinery through an intricate series of conserved events. Long non-coding RNAs (IncRNAs) are emerging as important regulators of stressinduced cascades, for their ability to mediate post-transcriptional responses. Consistently, many of them are specifically expressed under stress conditions and a few have been already functionally linked to these processes, thus further supporting a role in stress management. In this review we survey different archetypes of IncRNAs specifically implicated in the regulation of nucleolar functions and translation reprogramming during stress responses.
\end{abstract}

doi: $10.15698 /$ cst2019.01.172

Received originally: 29.04 .2018

in revised form: 10.10.2018,

Accepted 11.10.2018,

Published 05.12.2018.

Keywords: InCRNAs, ISR, IRES, UORFs, nucleolus, stress response, adaptation, ribosome biogenesis.
Abbreviations:
DFC - dense fibrillar components,
$F C$ - fibrillar center,
GC-granular component,
IGS - intergenic spacer,
IRES - internal ribosome entry site,
IncRNA - long non-coding RNA
mTOR-mammalian target of
rapamycin,
NoDS - nucleolar detention sequence,
rRNA - ribosomal RNA,
TORC - TOR complex,
treRNA - translational regulatory
InCRNA,
UORF - upstream open reading frame,
UTR - untranslated region.

\section{INTRODUCTION}

Unfavourable environmental conditions trigger cellular responses that help minimize and/or repair the damage experienced by the cell. During stress responses, most of the biosynthetic processes of the cell are reduced or shut down, to spare energy and preserve genome integrity, while selected pathways that help the recovery are specifically activated. Occurring in a contest of global transcriptional repression, responses to stress often involve epigenetic and posttranscriptional events [1].

Ribosomes, the core components of the translation apparatus, are molecular machineries composed by four dif- ferent ribosomal RNAs (rRNAs) and about 79 ribosomal proteins. Ribosome biogenesis is initiated in the nucleolus with the transcription of the rRNAs, and requires the coordinated activity of all the three polymerases together with a large number of transcription factors, nucleases and small RNAs that contribute to the processing and maturation of the rRNAs [2]. Utilizing about $80 \%$ of the cellular total energy, ribosome biogenesis is tightly regulated by the availability of nutrients and directly connected to cell cycle regulation, cell growth and apoptosis [3]. It follows that the nucleolus is a major sensor of stress and that the exposure to different stressors, including DNA damage, 


\section{BOX 1}

The mTOR pathway. The mammalian Target of Rapamycin (or mTOR) is a member of the phosphatidylinositol 3-kinase (PI3K)-related kinases. mTOR integrates the intracellular energetic status (ATP/AMP ratio) and the availability of nutrients and growth factors to activate cell metabolism and promote cell growth. Specifically, mTOR promotes de novo synthesis of lipids, nucleotides and proteins while inhibiting autophagy. mTOR exists in two different complexes the TOR complex 1 (TORC1) and the TORC2 complex. Differently from complex 1 the TORC2 complex can be activated only by growth factors and the details of its regulation is poorly understood. Both complexes however are downstream of the PI3K pathway [52].

TORC1 promotes global translation by phosphorylating the translational inhibitor 4E-BP, an event that causes its release from the initiation factor $4 \mathrm{E}$ (eIF4E). Furthermore, TORC1 is responsible for the translation of a subset of RNAs containing a 5' OligoPyrimidine Tract (5'TOP) encoding for translational machinery components. Lastly, by phosphorylation of another target, the S6K, TORC1 controls ribosome biogenesis. Following TORC activation, S6K phosphorylates the ribosomal protein S6 and CAD (Gln-dependent carbamoyl-phosphate synthase, Asp carbamoyltransferase, dihydroorotase). This last event stimulates pyrimidine synthesis and thus rRNA biosynthesis [53].

Modulation of autophagy is mostly achieved by phosphorylation and inactivation of the pro-autophagic UNC-51-like kinase 1 (ULK1) [54].

Lipogenesis is under control of both mTORC1 and mTORC2, through phosphorylation of SREBPs, the master regulators of lipogenic genes. Specifically, SREBPs phosphorylation is mediated by S6K and AKT respectively [55].

heat shock, hypoxia, viral infection, and others, all converge to downregulate and rewire ribosome biogenesis and translation [4]. Integration of environmental signals with ribosome biogenesis and translation is mostly achieved through the mTOR pathway (BOX1). Favorable extracellular conditions are translated by MTOR into cellular mass through phosphorylation of two main targets: 4EBP1 and S6K. While phosphorylation of this last one induces transcription of the rRNAs and boosts ribosome biogenesis, phosphorylation of $4 \mathrm{EBP} 1$ results into the release of elF4E that become available for binding with other initiation factors, thus leading to translation initiation [5]. Different stressors, not only affect the synthesis of functional ribosomes, but also regulate the rates of protein synthesis by triggering the so-called integrated stress response or ISR [6]. The ISR is triggered by different kinase receptors each activated by a different stimulus (e.g., viral infection, amino acid deprivation, ER stress...) and all converging to phosphorylation of elF2alpha, that blocks CAP-dependent translation in favour of ATF4 activation and non-canonical translation [6]. Translational rewiring upon stress is a key driver of cell plasticity and as such it is essential for many biological processes including regulation of lifespan [3] and cancer progression [7-9], therefore a deep understanding of this process will have important biological and therapeutic implications.

The last decade has witnessed an increased interest in IncRNAs, transcripts longer that 200 nucleotides that do not encode for proteins. Due to their pivotal role in the regulation of epigenetic and post-transcriptional events, they have been increasingly linked to stress responses. Here we summarize and discuss the existing knowledge about the role of these fascinating molecules in nucleolar stress and translational rewiring (Table 1).

\section{LnCRNAs in RIBOSOME BIOGENESIS}

Nucleoli are membrane-less bodies within the nucleus in which the early steps of ribosome biogenesis take place. Nucleoli are divided into different compartments: the Fibrillar Center (FC), the Dense Fibrillar Components (DFC) and the Granular Component (GC). The transcription of rRNA genes by the RNA polymerase I takes place at the interface between FC and DFC, the resulting $47 \mathrm{~S}$ precursor is then processed in the DFC and the ribosomal subunits are finally assembled in the in the GC (Figure 1). The structure and composition of the nucleoli are dynamically regulated during the cell cycle and profoundly altered by environmental stress [10].

LncRNAs can interfere with ribosome biogenesis in the nucleoli in three different ways: (i) by affecting nucleolar structure, (ii) by affecting rRNA and/or ribosomal protein production (iii) or by affecting rRNA and/or ribosomal protein maturation.

The nucleolar compartment assembles through phase separation of its molecular components and its subcompartments are made of coexisting liquid phases [11]. Phase transition is caused by interaction of intrinsic disordered domain containing proteins, such as fibrillarin, nucleolin and nucleophosmin, with non-coding RNAs, thus underlining the importance of the RNA for the maintenance of nucleolar structure and function. Supporting this view, recombinant fibrillarin and nucleophosmin form liquid droplets when combined with rRNA in vitro and, if mixed, the droplets will recapitulate the structure of nucleoli [11]. In addition, Alu-related B1 RNAs, polymerase II transcripts of about 250 nucleotides, are also enriched in the nucleoli and essential for nucleolar integrity. A recent study revealed that overexpression of these transcripts is sufficient to increase the size of nucleoli and the pre-rRNA 
TABLE 1. LncRNAs archetypes regulating nucleolar functions and translation reprogramming during stress responses.

\begin{tabular}{|c|c|c|c|}
\hline Name & Function & Inducing stress & Reference \\
\hline Ribosome InterGenic Spacer (IGS) & $\begin{array}{l}\text { Protein immobilization in nu- } \\
\text { cleolus }\end{array}$ & Heat shock and acidosis & {$[13,14]$} \\
\hline $\begin{array}{l}\text { Promoter And Pre-rRNA AntiSense } \\
\text { (PAPAS) }\end{array}$ & rDNA silencing & $\begin{array}{l}\text { Quiescence and hypotonic } \\
\text { stress }\end{array}$ & {$[15,16,17]$} \\
\hline SLERT & $\begin{array}{l}\text { Pre-rRNA transcription promo- } \\
\text { tion }\end{array}$ & Oncogenic stress & [18] \\
\hline SAMMSON & rRNA maturation & Oncogenic stress & [19] \\
\hline Circular ANRIL (circANRIL) & rRNA maturation & / & [21] \\
\hline ZFAS1 & Ribosome assembly regulation & Oncogenic stress & [39] \\
\hline Uchl1 & Translation promotion & / & {$[40]$} \\
\hline BACE1-AS (BACE1) & $\begin{array}{l}\text { mRNA and protein level regula- } \\
\text { tion }\end{array}$ & $\begin{array}{l}\text { Hyperthermia, serum starva- } \\
\text { tion, } A \beta 1-42 \text {, hydrogen per- } \\
\text { oxide or glucose shock }\end{array}$ & [41] \\
\hline $\begin{array}{l}\text { Natural Antisense RNA Zeb2 (Zeb2- } \\
\text { NAT) }\end{array}$ & Alternative splicing regulation & Not known & [45] \\
\hline $\begin{array}{l}\text { Translational Regulatory IncRNA } \\
\text { (treRNA) }\end{array}$ & $\begin{array}{l}\text { E-Cadherin translation supres- } \\
\text { sion }\end{array}$ & Oncogenic stress & {$[46]$} \\
\hline Neighbour of BRCA1 gene 2 (NRB2) & AMPK activity promotion & Energy stress & [47] \\
\hline
\end{tabular}

processing, while their depletion leads to dispersion of nucleoli [12].

Environmental stressors such as heat shock and acidosis cause IncRNA-dependent changes in nucleolar organization and structure. Jacob and colleagues showed that ribosome InterGenic Spacer (IGS) RNAs are induced upon stress, such as heat shock and acidosis, from very defined regions separating individual rDNA transcription units [13]. IGS RNAs target proteins containing NucleOlar Detention Sequences (NoDS) and immobilise them in the nucleolus [14]. Accumulation of IGS RNAs coincide with the formation of detention centers in the nucleoli and termination of rRNA transcription [13]. IGS RNAs are clear examples of ncRNAs affecting ribosome biogenesis through changes in nucleolar structure.

An example of IncRNAs affecting rRNA and/or ribosomal protein production, is the IncRNA Promoter And PrerRNA AntiSense (PAPAS), whose levels are increased during quiescence [15] and hypotonic stress [16]. During quiescence, PAPAS recruits Suv4-20h2, thus promoting trimethylation of histone $\mathrm{H} 4$ at lysine 20 (H4K2Ome3) and transcriptional silencing of rRNA genes [15]. Under the condition of hypotonic stress instead, when Suv4-20h2 is degraded, the same IncRNA causes nucleosome repositioning through the NuRD complex leading again to rDNA silencing [17].

A further example of a IncRNA regulating ribosome biogenesis is SLERT, a box H/ACA small nucleolar RNA
(snoRNA)-ended IncRNA [18]. SLERT is expressed in embryonic stem cells and in a number of human cancer cell lines and requires H/ACA snoRNAs at both ends for its correct processing and localization to the nucleoli. SLERT promotes pre-rRNA transcription by binding to DEAD-box RNA helicase DDX21 and blocking its inhibitory activity on the RNA polymerase I. Inhibition of SLERT reduces tumorigenic potential in vitro and in vivo in xenograft models [18].

An example of the third category (IncRNA or by affecting rRNA and/or ribosomal protein maturation) comes from our laboratory. We recently showed that the IncRNA SAMMSON is required for proper rRNA maturation in the mitochondria and in the nucleus of melanoma cells. Its activity ensures the coordination of the two translation machineries to avoid the emergence of proteotoxic stress [19]. SAMMSON exerts its function by directly interacting with three major regulators of ribosome biogenesis in the two compartments: XRN2, CARF and p32. By favouring the formation of an aberrant complex between p32 and CARF, SAMMSON retains CARF in the cytosol and impairs the binding to its natural partner XRN2, in the nucleus. Since p32 and XRN2 are involved in ribosome biogenesis in the mitochondria and nucleoli respectively, by redirecting CARF affinities, SAMMSON affects their cellular localization and enhances concertedly their functions [19].

Recently also circular RNAs (circRNAs) [20], that derive from back splicing of coding and non-coding genes, have been implicated in the regulation of nucleolar functions. 


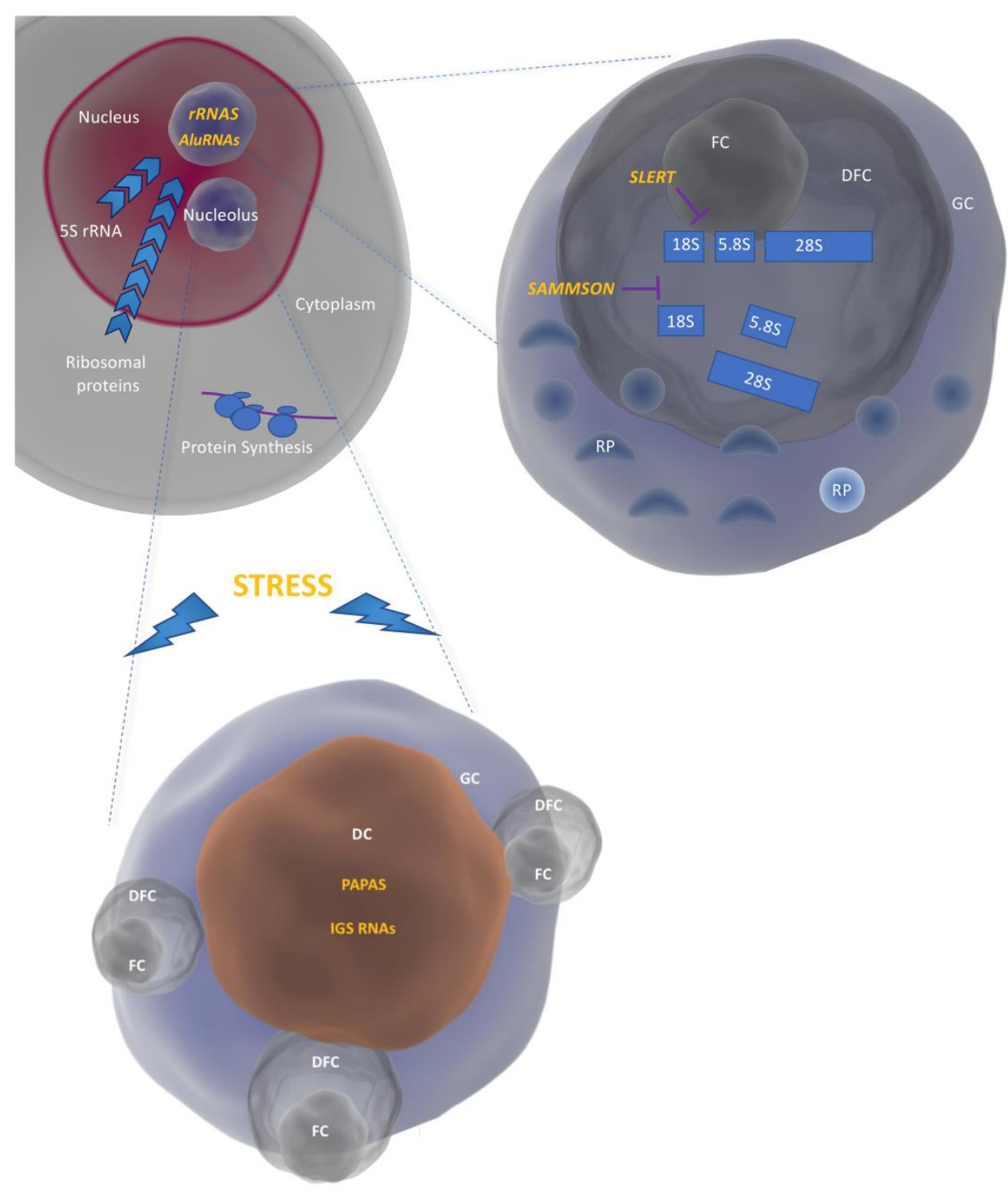

FIGURE 1: Compartmentalization of ribosome biogenesis in the nucleoli. The rRNAs are transcribed by the RNA polymerase I as a single precursor (47S) at the interface between the FC and the DFC. The mature rRNAs are produced in the DFC and assembled into large and small ribosomal subunits by binding to the ribosomal proteins (RP) coming from the cytoplasm and the $5 \mathrm{~S}$ (produced in the nucleoplasm) in the GC. Interaction of rRNA and AluRNAs with proteins leads to the formation of nucleoli through liquid-liquid phase separation. Under conditions of stress, IGS RNAs and PAPAs are upregulated thus leading to nucleolar remodeling and rRNA transcriptional silencing respectively. Nucleolar remodeling results in the formation of DC (Detention Centers). SLERT and SAMMSON regulate rRNA transcription and processing respectively.

The IncRNA ANRIL, which is transcribed at chromosome 9p21, for example is able to form RNA circles (circANRIL). Expression of the circular form of ANRIL increases p53 expression and induces apoptosis [21]. Holdt et al. showed that circANRIL interacts with the protein pescadillo

zebrafish homologue 1 (PES1), a component of the PES1-BOP1-WDR12 (PeBoWe) complex. qPCR analysis and Northern blotting showed an accumulation of $32 \mathrm{~S}$ and $36 \mathrm{~S}$ intermediates in circANRIL overexpressing cells. These findings all together suggest that circANRIL regulates rRNA maturation through PeBoWe complex and it could therefore trigger nuclear stress and p53 activation [21].

\section{ROLE OF IncRNAs IN TRANSLATIONAL REWIRING}

Under conditions of stress, the cell undergoes translational reprograming, where global translation is downregulated while essential factors for the recovery are still synthetized through alternative translation pathways [22]. Shift from global to selective translation is mostly achieved by modifi- cation of the translation initiation process. Global translation, also known as cap-dependent translation, relies on the recognition of the 7-methylguanosine ( $\left.m^{7} \mathrm{Gppp}\right)$ in the 5 -cap structure by eukaryotic initiation factor $4 \mathrm{E}$ and on the sequential assembly of initiation factors on the mRNA [23-25]. Under different stress conditions, stress sensing kinases (see Figure 2) get activated and prime the phosphorylation of Eukaryotic Initiation Factor $2 \alpha$ (elF2 $\alpha$ ) at serine 51, a condition that impairs the formation of the ternary complex necessary for cap-dependent translation [6]. In these conditions, different structures and sequences on the $5^{\prime}$ untranslated region (UTR) are used to recruit the ribosomes and ensure the translation of proteins required to overcome the stress. The most common way to activate cap-independent translation initiation are Upstream Open Reading Frames (uORFs) and Internal Ribosome Entry Site (IRES) [26, 27]. IRES are sequences in the $5^{\prime}$-UTR of coding transcripts, able to form complex structures that directly recruit the mRNAs to the ribosome without the need of 
most (and sometimes all) the initiation factors [24, 25]. Although first identified in viral RNAs [28], these sequences have been found also in the $5^{\prime}$-UTR of many oncogenes and tumor suppressors [29] including c-Myc [30], p53 [31] and $B c / 2$ [32].

Although IncRNAs are either not or only rarely translated into (small) peptides [33,34], profiling of ribosomeassociated RNAs has revealed that a large fraction of noncoding transcripts are associated with ribosomes [35-38]. This finding raises the intriguing possibility that several IncRNAs may contribute to the regulation of ribosome biogenesis and/or functions. LncRNA could affect translation in different ways: (i) by affecting ribosome assembly, (ii) by recruiting specific transcripts to the ribosome (ii) by masking (and unmasking) uORFs and/or IRES (iii) by interfering with translation factor activity or with specific signalling pathways.

Although these findings need further confirmation, ZFAS1 could be an example of a IncRNA regulating ribosome assembly. ZFAS1 was identified as a IncRNA binding to the light polysome fraction whose expression is induced during ribosome biogenesis in breast cancer cell [39].

Examples of IncRNAs regulating transcript recruitment to the ribosome are Uchl1 and BACE1-AS. It was recently demonstrated that the mouse IncRNA Uchl1 translocates to the cytoplasm upon mTORC1 activation, to promote translation of its own antisense transcript by base pairing to its $5^{\prime}$-end and enhancing recruitment of the ribosome [40]. BACE1-AS, the antisense to $\beta$-secretase 1 (BACE1), is elevated in brain of individuals with Alzheimer's disease [41]. BACE1-AS is able to stabilize the levels of BACE1 mRNA and increase, through an unknown mechanism, the levels of $\beta$-secretase 1 in response to different stressors [41].

An elegant example of the third category is Natural Antisense RNA Zeb2 (Zeb2-NAT). An IRES sequence for instance is hidden in an intron in the 5'-UTR of Zeb2, a transcriptional repressor of E-cadherin and master regulator of epithelial-to-mesenchymal transition, an essential process during development [42] and cancer progression [43, 44]. Alternative splicing of the intron containing the IRES is regulated by Zeb2-NAT [45]. During the induction of EMT, Zeb2NAT gets upregulated and base-pairs to Zeb2 mRNA thus causing intron retention. Inclusion of the IRES sequence increases Zeb2 translation and thus leads to the downregulation of E-cadherin [45].

Another IncRNA implicated in translational regulation and EMT is the Translational Regulatory IncRNA (treRNA). TreRNA is upregulated in lymphonode metastasis in breast cancer and its expression is associated with invasive behavior in vitro and in vivo [46]. Further analysis showed that treRNA binds to EIF4G to suppress E-cadherin translation,

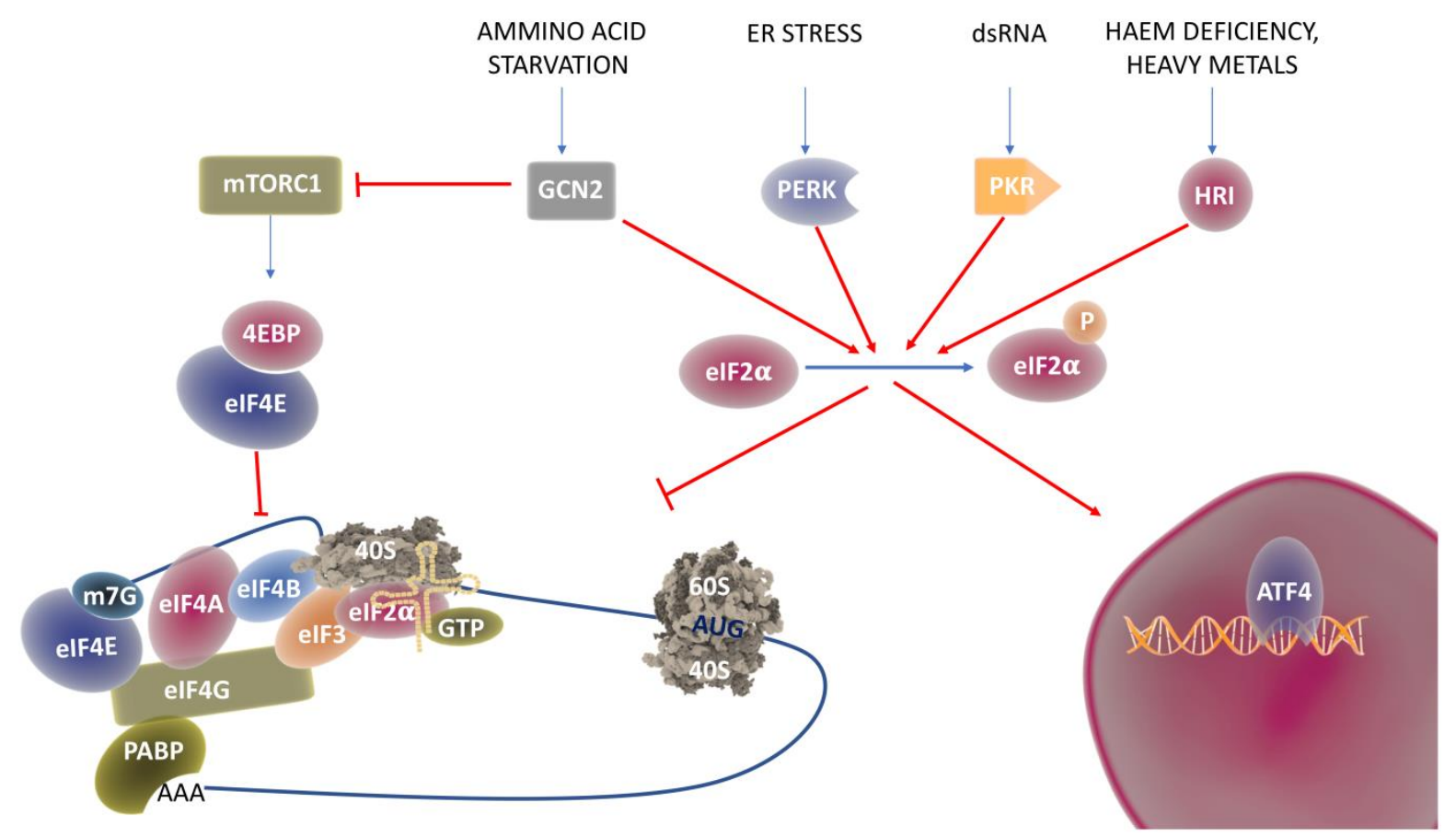

FIGURE 2: The ISR in translational reprograming. Environmental cues are able to turn off mTORC1, thus impeding phosphorylation of 4EBP and release of elF4E, the initiation factor responsible for $\mathrm{m} 7 \mathrm{G}$ cap recognition; this process leads to cap-dependent translational repression. In addition, different stimuli activate the stress sensor kinases GCN2, PERK, PKR or HRI that in turn phosphorylate elF4 $\alpha$. Phospo ser51 elF4 $\alpha$ cannot exchange anymore GDP and GTP therefore formation of the ternary complex between the small ribosomal subunit, elF4 $\alpha$ and the initiator tRNAMeti is inhibited. While general translation is inhibited, special/selective translation is initiated by activation of the ATF4 transcriptional program. 
in a 3'-UTR dependent manner [46]. This last one might be an example of the fourth category.

One further example in this (fourth?) category is the IncRNA neighbour of BRCA1gene 2 (NRB2), that is induced under energy stress [47]. NRB2 interacts with AMPK to promote its activity. Downregulation of NRB2 results in unchecked cell cycling/apoptotic responses and increased tumour development in xenograft models [47].

\section{CONCLUSIONS}

Since stress response pathways are essential to restore cellular homeostasis, their alteration and misuse are at the origin of pathologies like cancer development/progression [3] and neurodegenerative disorders [48]. The importance of ribosome biogenesis and translational regulation in a pathological context, is corroborated by the number of compounds targeting these processes currently in the clinic [49].

Given its essential roles in normal cells, however, modulating translation and ribosome biogenesis in a targeted manner remains a major challenge. Importantly, IncRNAs often exhibit cell-specific expression patterns $[50,51]$ and therefore they would be attractive "druggable" targets.

While the dark side of the genome comes to light, new examples of IncRNAs regulating ribosome biogenesis and protein synthesis emerge. It is very likely that the mechanisms described in this review are only the tip of the iceberg and new mechanisms will be soon uncovered and described. LncRNAs could for instance affect the recognition of uORFs, affect the modification pattern of rRNAs and mRNAs, help the recruitment of specific sets of RNAs to the ribosome, thus contributing not only to global regulation of

\section{REFERENCES}

1. Lakhotia SC (2012). Long non-coding RNAs coordinate cellular responses to stress. Wiley Interdiscip Rev RNA 3(6): 779-796. doi: 10.1002/wrna.1135

2. Ruggero D (2012). Revisiting the Nucleolus: From Marker to Dynamic Integrator of Cancer Signaling. Sci Signal 5(241): pe38. doi: 10.1126/scisignal.2003477

3. Maclnnes AW (2016). The role of the ribosome in the regulation of longevity and lifespan extension. Wiley Interdiscip Rev RNA 7(2): 198212. doi: 10.1002/wrna.1325

4. Boulon S, Westman BJ, Hutten S, Boisvert FM, Lamond AI (2010). The nucleolus under stress. Mol Cell 40(2): 216-227. doi: 10.1016/j.molcel.2010.09.024

5. Zoncu R, Efeyan A, Sabatini DM (2011). mTOR: from growth signal integration to cancer, diabetes and ageing. Nat Rev Mol Cell Biol 12(1): 21-35. doi: $10.1038 / \mathrm{nrm} 3025$

6. Pakos-Zebrucka K, Koryga I, Mnich K, Ljujic M, Samali A, Gorman AM (2016). The integrated stress response. EMBO Rep 17(10): 13741395. doi: 10.15252/embr.201642195

7. Falletta $P$, Sanchez-del-Campo L, Chauhan J, Effern M, Kenyon A, Kershaw CJ, Siddaway R, Lisle R, Freter R, Daniels MJ, Lu X, Tüting T, Middleton M, Buffa FM, Willis AE, Pavitt G, Ronai ZeA, Sauka-Spengler T, Hölzel M, Goding CR (2017). Translation reprogramming is an evolutionarily conserved driver of phenotypic plasticity and ribosomal functions, but also to the heterogeneity of the ribosome population. A systematic study of IncRNAs implicated in ribosome biogenesis and translational reprogramming would ultimately help clarifying the reasons for the association of these molecules with the ribosomes and their inability to code, thus opening new possibilities in translational research.

\section{ACKNOWLEDGMENTS}

Figures were prepared using Somersault libraries available from www.somersault1824.com. Eleonora Leucci's work was supported by the "King Baudouin Foundation" (ZKD2839). Lucas Goedert's work was supported by grant\#2017/16363-6 and grant\#2014/07726-0, São Paulo Research Foundation (FAPESP).

\section{CONFLICT OF INTEREST}

The authors declare no conflict of interest.

\section{COPYRIGHT}

(C) 2019 Verheyden et al. This is an open-access article released under the terms of the Creative Commons Attribution (CC BY) license, which allows the unrestricted use, distribution, and reproduction in any medium, provided the original author and source are acknowledged.

Please cite this article as: Yvessa Verheyden, Lucas Goedert and Eleonora Leucci (2019). Control of nucleolar stress and translational reprogramming by IncRNAs. Cell Stress 3(1): 19-26. doi: 10.15698/cst2019.01.172

therapeutic resistance in melanoma. Genes Dev 31(1): 18-33. doi 10.1101/gad.290940.116

8. Sendoel A, Dunn JG, Rodriguez EH, Naik S, Gomez NC, Hurwitz B, Levorse J, Dill BD, Schramek D, Molina H, Weissman JS, Fuchs E (2017). Translation from unconventional $5^{\prime}$ start sites drives tumour initiation. Nature 541(7638):494-499. doi: 10.1038/nature21036

9. Rapino F, Delaunay S, Rambow F, Zhou Z, Tharun L, De Tullio P, Sin $O$, Shostak K, Schmitz $S$, Piepers J, Ghesquière B, Karim L, Charloteaux $B$, Jamart $D$, Florin $A$, Lambert $C$, Rorive $A$, Jerusalem $G$, Leucci $E$, Dewaele M, Vooijs M, Leidel SA, Georges M, Voz M, Peers B, Büttner $\mathrm{R}$, Marine J-C, Chariot A, Close $P$ (2018). Codon-specific translation reprogramming promotes resistance to targeted therapy. Nature 558(7711): 605-609. doi: 10.1038/s41586-018-0243-7

10. Németh A, Grummt I (2018). Dynamic regulation of nucleolar architecture. Curr Opin Cell Biol 52: 105-111. doi: 10.1016/j.ceb.2018.02.013

11. Feric M, Vaidya N, Harmon TS, Mitrea DM, Zhu L, Richardson TM, Kriwacki RW, Pappu RV, Brangwynne CP (2016). Coexisting Liquid Phases Underlie Nucleolar Subcompartments. Cell 165(7): 1686-1697. doi: 10.1016/j.cell.2016.04.047

12. Herger MC, Pankert T, Seiler J, Németh A, Voit R, Grummt I, Rippe $\mathrm{K}$ (2015). Alu element-containing RNAs maintain nucleolar structure and function. EMBO J 34(22): 2758-2774. doi: 10.15252/embj.201591458 
13. Jacob MD, Audas TE, Uniacke J, Trinkle-Mulcahy L, Lee S (2013). Environmental cues induce a long noncoding RNA-dependent remodeling of the nucleolus. Mol Biol Cell 24(18): 2943-2953. doi: 10.1091/mbc.E13-04-0223

14. Audas TE, Jacob MD, Lee S (2012). Immobilization of Proteins in the Nucleolus by Ribosomal Intergenic Spacer Noncoding RNA. Mol Cell 45(2): 147-157. doi: 10.1016/j.molcel.2011.12.012

15. Bierhoff H, Dammert MA, Brocks D, Dambacher S, Schotta G, Grummt I (2014). Quiescence-Induced LncRNAs Trigger H4K20 Trimethylation and Transcriptional Silencing. Mol Cell 54(4): 675-682. doi: 10.1016/j.molcel.2014.03.032

16. Zhao Z, Dammert MA, Grummt I, Bierhoff H (2016). IncRNAInduced Nucleosome Repositioning Reinforces Transcriptional Repression of rRNA Genes upon Hypotonic Stress. Cell Rep 14(8): 1876-1882. doi: 10.1016/j.celrep.2016.01.073

17. Zhao Z, Dammert MA, Hoppe S, Bierhoff H, Grummt I (2016). Heat shock represses rRNA synthesis by inactivation of TIF-IA and IncRNAdependent changes in nucleosome positioning. Nucleic Acids Res 44(17): 8144-8152. doi: 10.1093/nar/gkw496

18. Xing $Y-H$, Yao R-W, Zhang $Y$, Guo C-J, Jiang S, Xu G, Dong R, Yang L, Chen L-L (2017). SLERT Regulates DDX21 Rings Associated with Pol I Transcription. Cell 169(4): 664-678.e616. doi: 10.1016/j.cell.2017.04.011

19. Vendramin R, Verheyden $Y$, Ishikawa $H$, Goedert L, Nicolas E, Saraf K, Armaos A, Ponti RD, Izumikawa K, Mestdagh P, L.J. DL, Gian GT, Takahashi N, Marine J-C, Leucci E (2018). SAMMSON fosters cancer cell fitness by enhancing concertedly mitochondrial and cytosolic translation. Nat Struct Mol Biol 25(11):1035-1046. doi: 10.1038/s41594-018-0143-4

20. Ebbesen KK, Kjems J, Hansen TB (2016). Circular RNAs: Identification, biogenesis and function. Biochim Biophys Acta 1859(1): 163-168. doi: 10.1016/j.bbagrm.2015.07.007

21. Holdt LM, Stahringer A, Sass K, Pichler G, Kulak NA, Wilfert W, Kohlmaier A, Herbst A, Northoff BH, Nicolaou A, Gabel G, Beutner F, Scholz M, Thiery J, Musunuru K, Krohn K (2016). Circular non-coding RNA ANRIL modulates ribosomal RNA maturation and atherosclerosis in humans. Nat Commun 7: 12429. doi: 10.1038/ncomms12429

22. Liu B, Qian S-B (2013). Translational reprogramming in cellular stress response. Wiley Interdiscip Rev RNA 5(3): 301-305. doi: 10.1002/wrna.1212

23. Sonenberg N, Hinnebusch AG (2009). Regulation of Translation Initiation in Eukaryotes: Mechanisms and Biological Targets. Cell 136(4): 731-745. doi: 10.1016/j.cell.2009.01.042

24. Jackson RJ, Hellen CUT, Pestova TV (2010). The mechanism of eukaryotic translation initiation and principles of its regulation. Nat Rev Mol Cell Biol 11(2): 113-127. doi: 10.1038/nrm2838

25. Hinnebusch AG, Ivanov IP, Sonenberg N (2016). Translational control by $5^{\prime}$-untranslated regions of eukaryotic mRNAs. Science 352(6292): 1413-1416. doi: 10.1126/science.aad9868

26. Chen C-Y, Macejak DG, Oh S-K, Sarnow P (1993). Translation Initiation by Internal Ribosome Binding of Eukaryotic mRNA Molecules. The Translational Apparatus. Springer, Boston, MA. pp 229-240.

27. Leppek K, Das R, Barna M (2018). Functional 5' UTR mRNA structures in eukaryotic translation regulation and how to find them. Nat Rev Mol Cell Biol 19(3): 158-174. doi: 10.1038/nrm.2017.103

28. Pelletier J, Sonenberg N (1988). Internal initiation of translation of eukaryotic mRNA directed by a sequence derived from poliovirus RNA. Nature 334(6180): 320-325. doi: 10.1038/334320a0
29. Hellen CU, Sarnow $P$ (2001). Internal ribosome entry sites in eukaryotic mRNA molecules. Genes Dev 15(13): 1593-1612. doi: $10.1101 /$ gad. 891101

30. Stoneley $M$, Paulin FEM, Quesne JPCL, Chappell SA, Willis AE (1998). C-Myc 5' untranslated region contains an internal ribosome entry segment. Oncogene 16(3): 423-428. doi: 10.1038/sj.onc.1201763

31. Yang DQ, Halaby MJ, Zhang $Y$ (2006). The identification of an internal ribosomal entry site in the 5 '-untranslated region of $\mathrm{p} 53$ mRNA provides a novel mechanism for the regulation of its translation following DNA damage. Oncogene 25(33): 4613-4619. doi: 10.1038/sj.onc. 1209483

32. Sherrill KW, Byrd MP, Van Eden ME, Lloyd RE (2004). BCL-2 translation is mediated via internal ribosome entry during cell stress. $J$ Biol Chem 279(28): 29066-29074. doi: 10.1074/jbc.M402727200

33. Guttman M, Russell P, Ingolia NT, Weissman JS, Lander ES (2013). Ribosome profiling provides evidence that large noncoding RNAs do not encode proteins. Cell 154(1): 240-251. doi: 10.1016/j.cell.2013.06.009

34. Bánfai B, Jia H, Khatun J, Wood E, Risk B, William E Gundling, Jr., Kundaje A, Gunawardena HP, Yu Y, Xie L, Krajewski K, Strahl BD, Chen $X$, Bickel P, Giddings MC, Brown JB, Lipovich L (2012). Long noncoding RNAs are rarely translated in two human cell lines. Genome Res 22(9): 1646-1657. doi: 10.1101/gr.134767.111

35. van Heesch $S$, van Iterson $M$, Jacobi J, Boymans S, Essers PB, de Bruijn E, Hao W, Maclnnes AW, Cuppen E, Simonis M (2014). Extensive localization of long noncoding RNAs to the cytosol and mono- and polyribosomal complexes. Genome Biol 15(1): R6. doi: 10.1186/gb-2014-15-1-r6

36. Ingolia NT, Brar GA, Stern-Ginossar N, Harris MS, Talhouarne GJS, Jackson SE, Wills MR, Weissman JS (2014). Ribosome profiling reveals pervasive translation outside of annotated protein-coding genes. Cell $\operatorname{Rep}$ 8(5): 1365-1379. doi: 10.1016/j.celrep.2014.07.045

37. Ruiz-Orera J, Messeguer X, Subirana JA, Alba MM (2014). Long non-coding RNAs as a source of new peptides. Elife 3: e03523. doi: 10.7554/elife.03523

38. Aspden JL, Eyre-Walker YC, Phillips RJ, Amin U, Mumtaz MAS, Brocard M, Couso J-P (2014). Extensive translation of small Open Reading Frames revealed by Poly-Ribo-Seq. Elife 3: e03528. doi: 10.7554/eLife.03528

39. Hansji H, Leung EY, Baguley BC, Finlay GJ, Cameron-Smith D, Figueiredo VC, Askarian-Amiri ME (2016). ZFAS1: a long noncoding RNA associated with ribosomes in breast cancer cells. Biol Direct 11(1): 1-25. doi: 10.1186/s13062-016-0165-y

40. Carrieri C, Cimatti L, Biagioli M, Beugnet A, Zucchelli S, Fedele S, Pesce E, Ferrer I, Collavin L, Santoro C, Forrest AR, Carninci P, Biffo S, Stupka E, Gustincich $S$ (2012). Long non-coding antisense RNA controls Uchl1 translation through an embedded SINEB2 repeat. Nature 491(7424): 454-457. doi: 10.1038/nature11508

41. Faghihi MA, Modarresi F, Khalil AM, Wood DE, Sahagan BG Morgan TE, Finch CE, Laurent lii GS, Kenny PJ, Wahlestedt C (2008). Expression of a noncoding RNA is elevated in Alzheimer's disease and drives rapid feed-forward regulation of $\beta$-secretase. Nat Med 14(7): 723-730. doi: 10.1038/nm1784

42. Nieto MA (2013). Epithelial Plasticity: A Common Theme in Embryonic and Cancer Cells. Science 342(6159): 1234850-1234850. doi: $10.1126 /$ science. 1234850

43. Brabletz $T$, Kalluri R, Nieto MA, Weinberg RA (2018). EMT in cancer. Nat Rev Cancer 18(2): 128-134. doi: 10.1038/nrc.2017.118 
44. Shibue T, Weinberg RA (2017). EMT, CSCs, and drug resistance: the mechanistic link and clinical implications. Nat Rev Clin Oncol 14(10): 611-629. doi: 10.1038/nrclinonc.2017.44

45. Beltran M, Puig I, Pena C, Garcia JM, Alvarez AB, Pena R, Bonilla F, de Herreros AG (2008). A natural antisense transcript regulates Zeb2/Sip1 gene expression during Snail1-induced epithelialmesenchymal transition. Genes Dev 22(6): 756-769. doi: 10.1101/gad.455708

46. Gumireddy K, Li A, Yan J, Setoyama T, Johannes GJ, Orom UA, Tchou J, Liu Q, Zhang L, Speicher DW, Calin GA, Huang Q (2013). Identification of a long non-coding RNA-associated RNP complex regulating metastasis at the translational step. EMBO J 32(20): 26722684. doi: $10.1038 /$ emboj.2013.188

47. Liu X, Xiao Z-D, Han L, Zhang J, Lee S-W, Wang W, Lee H, Zhuang L, Chen J, Lin H-K, Wang J, Liang H, Gan B (2016). LncRNA NBR2 engages a metabolic checkpoint by regulating AMPK under energy stress. Nat Cell Biol 18(4): 431-442. doi: 10.1038/ncb3328

48. M K, Mridu K, Ce M, SI A (2017). Regulation of mRNA Translation in Neurons-A Matter of Life and Death. Neuron 96(3): 616-637. doi: 10.1016/j.neuron.2017.09.057

49. Bhat M, Robichaud N, Hulea L, Sonenberg N, Pelletier J, Topisirovic I (2015). Targeting the translation machinery in cancer. Nat Rev Drug Discov 14(4): 261-278. doi: 10.1038/nrd4505
50. Cabili MN, Trapnell C, Goff L, Koziol M, Tazon-Vega B, Regev A, Rinn JL (2011). Integrative annotation of human large intergenic noncoding RNAs reveals global properties and specific subclasses. Genes Dev 25(18): 1915-1927. doi: 10.1101/gad.17446611

51. Iyer MK, Niknafs YS, Malik R, Singhal U, Sahu A, Hosono Y, Barrette TR, Prensner JR, Evans JR, Zhao S, Poliakov A, Cao X, Dhanasekaran SM, Wu Y-M, Robinson DR, Beer DG, Feng FY, Iyer HK, Chinnaiyan AM (2015). The landscape of long noncoding RNAs in the human transcriptome. Nat Genet 47(3): 199-208. doi: 10.1038/ng.3192

52. Shimobayashi M, Hall MN (2014). Making new contacts: the mTOR network in metabolism and signalling crosstalk. Nat Rev Mol Cell Biol 15(3): 155-162. doi: 10.1038/nrm3757

53. Ma XM, Blenis J (2009). Molecular mechanisms of mTOR-mediated translational control. Nat Rev Mol Cell Biol 10(5): 307-318. doi: $10.1038 / \mathrm{nrm} 2672$

54. Kim J, Kundu M, Viollet B, Guan K-L (2011). AMPK and mTOR regulate autophagy through direct phosphorylation of Ulk1. Nat Cell Biol 13(2): 132-141. doi: 10.1038/ncb2152

55. Lamming DW, Sabatini DM (2013). A Central role for mTOR in lipid homeostasis. Cell Metab 18(4): 465-469. doi: 10.1016/j.cmet.2013.08.002 